\title{
28 Research Square \\ Predictive values of serum soluble CD40 ligand in acute appendicitis in children
}

\section{Wun-Yan Huang}

China Medical University Hospital

\section{En-Pei Lee}

Linkou Chang Gung Memorial Hospital

\section{Yu-Jun Chang}

Changhua Christian Hospital

Chieh-Chung Lin

China Medical University Hospital

Han-Ping Wu ( $\sigma$ arthur1226@gmail.com )

China Medical University Hospital

\section{Research Article}

Keywords: Soluble CD40 ligand, appendicitis, prediction, children

Posted Date: December 17th, 2020

DOI: https://doi.org/10.21203/rs.3.rs-120425/v1

License: (c) (i) This work is licensed under a Creative Commons Attribution 4.0 International License. Read Full License 


\section{Abstract}

Appendicitis is one of the most common abdominal emergencies in children. Clinicians cannot easily distinguish between non-perforated and perforated appendicitis in children through physical and laboratory tests. An abdominal computed tomography is a common tool for diagnosis. However, excessive radiation exposure is not suitable for children. Serum soluble CD40 ligand (SCD40L) is an inflammatory biomarker. The purpose of our study was to predict pediatric appendicitis and perforated appendicitis using SCD40L. All pediatric patients with suspected appendicitis were tested for serum sCD40L within $72 \mathrm{~h}$ of the symptom onset. SCD40L levels were compared between patients with a normal appendix, appendicitis, and a perforated appendicitis. The diagnostic performance of SCD40L was calculated, and receiver operating characteristic curves were drawn. Of 116 patients, 62 had nonperforated appendicitis, 44 had perforated appendicitis, and 10 had normal appendices. The sensitivity of SCD40L in predicting appendicitis was 1.00 , while the specificity in predicting perforation was 1.00 . The best cutoff point was found to be $178.00 \mathrm{pg} / \mathrm{ml}$ for predicting appendicitis and $308.26 \mathrm{pg} / \mathrm{ml}$ for perforation. SCD $40 \mathrm{~L}$ is an excellent predictor of pediatric appendicitis. SCD $40 \mathrm{~L}$ below $90.04 \mathrm{pg} / \mathrm{ml}$ can rule out appendicitis and above $301.00 \mathrm{pg} / \mathrm{ml}$ can rule in appendicitis.

\section{Introduction}

Appendicitis is a common abdominal emergency seen in a pediatric emergency department (PED). ${ }^{1-3}$ Typical appendicitis begins with pain around the umbilical region and then develops into pain in the lower right abdomen with fever, vomiting, and loss of appetite; however, clinical manifestations of atypical appendicitis are diverse. ${ }^{3}$ According to the presence or absence of perforation, cases can be divided into perforated appendicitis and nonperforated appendicitis. ${ }^{3-4}$ Many complications of perforated appendicitis are due to delayed diagnosis or even missed diagnosis. Delayed treatments may lead to severe peritonitis and even septic shock. ${ }^{4-5,7}$

There are some reports on how to diagnose atypical appendicitis in children, indicating diagnostic scoring systems, and serum laboratory tests such as for white blood cells or C-reactive protein. ${ }^{6-8}$ However, the accuracy of these diagnostic methods may not be good enough. Moreover, abdominal ultrasound and abdominal computed tomography (CT) are usually imaged in the PED, where abdominal CT has high specificity and sensitivity for the diagnosis of appendicitis in children. ${ }^{9}$ Abdominal CT may be the most common tool to diagnose pediatric appendicitis in the PED. However, high radiation from the CT remains a questionable issue and a potential disadvantage, which tends to increase the risk of malignancy in children. ${ }^{10}$ In recent years, more and more new inflamed serum biomarkers have been used in the diagnosis of appendicitis such as procalcitonin, interleukin 6, and 5-hydroxyindoleacetic acid, but good accuracy has not been achieved. ${ }^{11}$ Soluble CD40 ligand (SCD40L) is an inflammatory biomarker in some infectious diseases such as sepsis. CD40 ligand (CD40L), a member of the tumor necrosis factor family, and its soluble CD40 ligand (sCD40L) have prothrombogenic and proinflammatory properties inducing platelet aggregation. ${ }^{12}$ The aim of this study was to use serum SCD $40 \mathrm{~L}$ to predict acute 
appendicitis and perforated appendicitis in children. In addition, we also aimed to determine the different cutoff values of SCD40L based on how long the patient's symptoms were present to improve diagnostic accuracy of acute appendicitis.

\section{Materials And Methods}

\section{Patients population}

We prospectively enrolled pediatric patients admitted for clinically suspected acute appendicitis in the PED of a medical center between 2012 and 2015. The suspected acute appendicitis was reserved to cases with clinical signs and symptoms such as abdominal pain, loss of appetite, nausea, vomiting, fever, tenderness, and migration of pain in the right lower abdomen. Excluded patients were children with suspected acute appendicitis treated by non-surgical methods. A total of 116 pediatric patients with suspected appendicitis were enrolled. Histopathologic evaluation was performed to confirm diagnosis in acute appendicitis. The study protocol was approved by the Institution Review Board and ethics committee of Chang Gung Memorial Hospital, and it was conducted in accordance with the approved guidelines and the Declaration of Helsinki. Informed consent was obtained from a parent and/or legal guardian of children participating in the study. All methods were performed in accordance with the relevant protocols.

The following data were recorded on admission: age, sex, body temperature, time of onset of symptoms, and time of admission. On admission, blood samples from all patients were collected for further analysis. All the selected patients were tested once for serum SCD40L levels measured by enzyme linked immunosorbent assay (R\&D system, Minneapolis, MN, USA). Furthermore, we compared serum SCD40L levels among patients with normal appendices, acute appendicitis, and perforated appendicitis. All patients were divided into Group $\$ and Group II for further analysis. Group $₫$ was defined as the comparison between patients with normal appendices and acute appendicitis, and Group II indicated the comparison between patients with perforated appendicitis and non-perforated appendicitis..

\section{Statistics}

Statistical analysis used to compare values of SCD40L in each group includes the Mann-Whitney U test, Chi-square test, and the receiver operating characteristic (ROC) curve. Values are presented as mean \pm standard derivation (SD) and 95\% confidence intervals (Cls) in subgroups of Group囚and Group II. The

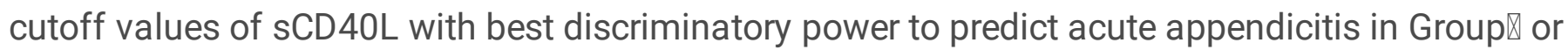
perforated appendicitis in Group II were analyzed from the ROC curves. Diagnostic performance, including sensitivity, specificity, area under the ROC curve (AUC), positive likelihood ratio (LR+), and negative likelihood ratio (LR-) of these different cutoff values were calculated using the SPSS software (version 22.0; SPSS Inc., Chicago, IL, USA).

\section{Results}


During the study period, data from 116 patients aged less than 18 years with suspected acute appendicitis were collected for this study. Of them, 62 patients had histologically proven non-perforated appendicitis, 44 had perforated appendicitis, and 10 had normal appendices. Their mean SCD 40L values are shown in Fig. 1. The mean SCD40L levels in patients with normal appendices, appendicitis, and perforated appendicitis were $145.69 \pm 65.41 \mathrm{pg} / \mathrm{ml}, 286.46 \pm 157.72 \mathrm{pg} / \mathrm{ml}$, and $397.80 \pm 177.91 \mathrm{pg} / \mathrm{ml}$, respectively $(P<0.05)$. The comparison of serum SCD40L levels among patients with normal appendices, appendicitis, and perforated appendicitis on the first 3 days after onset of symptoms is shown in Table 1 . Logistic regression analysis of SCD40L levels in Group I and Group II is shown in Table 2. The SCD40L levels showed a significant difference within Group I and Group II (both $\mathrm{P}<0.05$ ).

Table 1

Comparison of serum SCD40L levels between children with acute appendicitis and normal appendices, and between children with perforated appendicitis and non-perforted appendicitis

\begin{tabular}{|c|c|c|c|c|c|}
\hline \multirow{3}{*}{$\begin{array}{l}\text { Parameter } \\
\text { sCD40L } \\
(\mathrm{pg} / \mathrm{ml})\end{array}$} & \multicolumn{2}{|c|}{ Normal appendices } & \multicolumn{2}{|l|}{ Appendicitis } & \multirow{2}{*}{$\begin{array}{l}P \\
\text { value }\end{array}$} \\
\hline & Mean \pm SD (No.) & $95 \% \mathrm{Cl}$ & Mean \pm SD (No.) & $95 \% \mathrm{Cl}$ & \\
\hline & $\begin{array}{l}145.69 \pm 65.41 \\
(10)\end{array}$ & $98.90-192.48$ & $\begin{array}{l}286.46 \pm 157.72 \\
(106)\end{array}$ & 256.08-316.83 & 0.001 \\
\hline & \multicolumn{2}{|c|}{ Non-perforted appendicitis } & \multicolumn{2}{|c|}{ Perforated appendicitis } & \\
\hline sCD40L & Mean $\pm \mathrm{SD}($ No. $)$ & $95 \% \mathrm{Cl}$ & Mean $\pm \mathrm{SD}($ No. $)$ & $95 \% \mathrm{Cl}$ & \\
\hline$(\mathrm{pg} / \mathrm{ml})$ & $\begin{array}{l}207.44 \pm 72.23 \\
(62)\end{array}$ & $\begin{array}{l}189.10- \\
225.78\end{array}$ & $397.80 \pm 177.91(44)$ & $\begin{array}{l}343.71- \\
451.89\end{array}$ & $\begin{array}{l}< \\
0.001\end{array}$ \\
\hline
\end{tabular}

Table 2

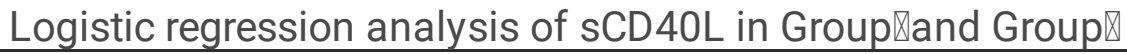

\begin{tabular}{|c|c|c|c|}
\hline & Odds ratio & $95 \% \mathrm{Cl}$ & $P$ value \\
\hline Group $\rrbracket$ & 1.019 & $1.005-1.033$ & 0.006 \\
\hline Group $\rrbracket$ & 1.018 & $1.011-1.025$ & $<0.0001$ \\
\hline \multicolumn{4}{|c|}{ Group®: Comparison of the patients with appendicitis and the patients with normal appendices } \\
\hline \multicolumn{4}{|c|}{$\begin{array}{l}\text { Group》: Comparison of the patients with perforated appendicitis and the patients with non-perfortec } \\
\text { appendicitis }\end{array}$} \\
\hline \multicolumn{4}{|c|}{ Cl: confidence interval } \\
\hline
\end{tabular}

In addition, we determined the cutoff values of our selected discriminators to predict acute appendicitis, and the diagnostic parameters, including sensitivity, specificity, LR+, LR-, and AUC (Table 3). The ROC 
curves are shown in Fig. 2. The AUCs of Group I and Group II were 0.83 and 0.87 , respectively. The best cutoff value of SCD40L in Group I was $178.00 \mathrm{pg} / \mathrm{ml}$, and the cutoff value in Group II was $308.26 \mathrm{pg} / \mathrm{ml}$. We further determined two cut-off points of SCD40L to 'rule in' or 'rule out' acute appendicitis for each group, shown in Table 4. In Group I, the cutoff value for SCD40L of $90.04 \mathrm{pg} / \mathrm{ml}$ had the highest sensitivity of 1.00 to rule out appendicitis, while $301.00 \mathrm{pg} / \mathrm{ml}$ had the highest specificity of 1.00 to rule in appendicitis. In Group II, the cutoff value of SCD $40 \mathrm{~L}$ of $180.95 \mathrm{pg} / \mathrm{ml}$ had the highest sensitivity to rule out perforated appendicitis, and $342.80 \mathrm{pg} / \mathrm{ml}$ had the highest specificity to rule in perforation.

Table 3

The best cutoff values of SCD $40 \mathrm{~L}$ in distinguishing acute appendicitis from normal appendices (Group $\mathbb{\text { ) }}$

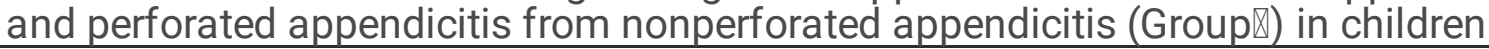

\begin{tabular}{|c|c|c|c|c|c|c|}
\hline & cut-off values (pg/ml) & Sensitivity & Specificity & LR+ & LR- & $\operatorname{AUC}(95 \% \mathrm{Cl})$ \\
\hline Group $\otimes$ & $>178.00$ & 0.73 & 0.90 & 7.26 & 0.30 & $0.83(0.75-0.89)$ \\
\hline Group $\mathbb{1}$ & $>308.26$ & 0.68 & 0.94 & 10.57 & 0.34 & $0.87(0.81-0.94)$ \\
\hline \multicolumn{7}{|c|}{ Group囚: Comparison of the patients with appendicitis and the patients with normal appendices } \\
\hline \multicolumn{7}{|c|}{$\begin{array}{l}\text { Group } \rrbracket: \text { Comparison of the patients with perforated appendicitis and the patients with non-perforted } \\
\text { appendicitis }\end{array}$} \\
\hline \multicolumn{7}{|c|}{ LR+: positive likelihood ratio; LR-: negative likelihood ratio; } \\
\hline \multicolumn{7}{|c|}{ AUC: area under the curve; $\mathrm{Cl}$ : confidence interval } \\
\hline
\end{tabular}

Table 4

The two cut-off values of SCD40L to rule out and rule in appendicitis and perforated appendicitis in children

\begin{tabular}{|c|c|c|c|c|c|c|}
\hline & cut-off values $(\mathrm{pg} / \mathrm{ml})$ & Sensitivity & Specificity & LR+ & LR- & $\operatorname{AUC}(95 \% \mathrm{Cl})$ \\
\hline \multirow[t]{2}{*}{ Group $\otimes$} & $>90.04$ & 1.00 & 0 & 1.0 & 0 & $0.83(0.75-0.89)$ \\
\hline & $>301.00$ & 0.35 & 1.00 & - & 0.65 & $0.83(0.75-0.89)$ \\
\hline \multirow[t]{2}{*}{ Group $\otimes$} & $>180.95$ & 1.00 & 0.50 & 2.0 & 0 & $0.87(0.81-0.94)$ \\
\hline & $>342.80$ & 0.59 & 1.00 & - & 0.41 & $0.87(0.81-0.94)$ \\
\hline \multicolumn{7}{|c|}{ Group®: Comparison of the patients with appendicitis and the patients with normal appendices } \\
\hline \multicolumn{7}{|c|}{$\begin{array}{l}\text { Group } \rrbracket: \text { Comparison of the patients with perforated appendicitis and the patients with non-perforted } \\
\text { appendicitis }\end{array}$} \\
\hline \multicolumn{7}{|c|}{ LR+: positive likelihood ratio; LR-: negative likelihood ratio; } \\
\hline \multicolumn{7}{|c|}{ AUC: area under the curve; $\mathrm{Cl}$ : confidence interval } \\
\hline
\end{tabular}




\section{Discussion}

Early diagnosis of appendicitis in children not only prevents perforation, abscess formation, and postoperative complications, but also reduces costs by shortening hospital stay. ${ }^{13}$ In young or preverbal children, history taking is difficult, and physical examination findings are equivocal. $6,14,15$ Clinicians have difficulties in diagnosing appendicitis immediately in these cases. Abdominal computed tomography is often used in these children with suspected appendicitis because of the fast result and high accuracy. However, the exposure to ionizing radiation and high healthcare costs should be considered. ${ }^{10}$ These concerns have led to the search for new diagnostic tools for predicting appendicitis. Thus, we tested the use of SCD40L as a predictor of pediatric appendicitis and perforated appendicitis in our study.

Our study demonstrated that SCD40L levels may be a good predictor for acute appendicitis and perforated appendicitis. As far as we know, this is the first study that SCD40L could be evaluated as a potential serum biomarker for predicting appendicitis in children. Based on our results, once children with clinically suspected acute appendicitis have serum SCD40L levels less than $90.04 \mathrm{pg} / \mathrm{ml}$, primary clinicians may exclude the possibility of acute appendicitis. However, once children have serum SCD40L levels exceeding $301.00 \mathrm{pg} / \mathrm{ml}$, the diagnosis of acute appendicitis could be confirmed. Furthermore, SCD40L may also serve as a potential predictor for perforated appendicitis. Clinically, SCD40L levels less than $180.95 \mathrm{pg} / \mathrm{ml}$ may be used to rule out perforation of the appendix while SCD40L levels exceeding $342.80 \mathrm{pg} / \mathrm{ml}$ could be evaluated to confirm perforated appendicitis. In contrast, primary clinicians need to pay more attention to an indeterminate zone in clinical practice because it is not easy to make decisions about children with clinically suspected appendicitis. In this indeterminate zone, primary care clinicians need more diagnostic aids to achieve accurate diagnosis for appendicitis and determine whether perforation has occurred or not. In addition, it is important to prevent progression to septic peritonitis. In this study, we found that SCD40L may be helpful in discriminating between children with acute appendicitis and those with normal appendices. Clinically, once the cutoff point of delta SCD4OL is greater than $178.00 \mathrm{pg} / \mathrm{ml}$, the probability of acute appendicitis will decidedly increase. In addition, once $\mathrm{sCD} 40 \mathrm{~L}$ is greater than $308.26 \mathrm{pg} / \mathrm{ml}$, the probability of perforated appendicitis will significantly increase. Based on our findings, the large AUCs of SCD40L may indicate its use as a helpful parameter in predicting both acute appendicitis and perforated appendicitis.

Our study revealed that SCD40L has a high sensitivity and specificity in predicting pediatric appendicitis. However, the role of SCD40L in appendicitis is novel, and it is possible that there are similarities with mechanisms observed in inflammatory and infectious diseases such as sepsis. ${ }^{12}$ CD 40, a type I transmembrane receptor protein that belongs to the TNF receptor superfamily, is expressed on a variety of cell types including platelets, immunity cells, endothelial cells, fibroblasts, and smooth muscle cells. CD40 becomes active within the cell after binding to CD40L, which is stored in unstimulated platelets. When the platelets are activated, CD 40L migrates to the platelet surface. Then, CD40L is cleaved and released becoming SCD40L, which binds to circulating monocytes and CD40 on endothelial cell surfaces. This stimulates the nuclear factor-kB signaling pathway with subsequent up-regulation of proinflammatory and prothrombotic factors. Thus, SCD40L plays an important role between immune 
responses and inflammation. ${ }^{16-19}$ Based on the related studies, we believe that SCD40L may be a useful inflammatory biomarker and could be applied in the diagnosis of appendicitis. Until now, none of the previous studies have reported about the association between SCD40L levels and appendicitis in children. Our study confirms that SCD40L is a potentially useful biomarker in diagnosing pediatric appendicitis and perforation of the appendix.

In conclusion, $\mathrm{SCD} 40 \mathrm{~L}$ may help the diagnosis of acute appendicitis and the prediction of perforation of the appendix in children. Therefore, we propose the addition of serum SCD40L testing to blood tests as a helpful diagnostic method in pediatric patients suspected of having acute appendicitis.

\section{Declarations}

\section{Acknowledgements}

None.

\section{Funding}

Not applicable.

\section{Availability of data and materials}

Not applicable.

\section{Authors' contributions}

W.Y.H. and H.P.W .conceived and designed the study. E.P.L. and Y.J.C. participated in data analysis. Y.J.C. and H.P.W. gathered the data. W.Y.H. and E.P.L. drafted the manuscript. H.P.W. and C.C.L. designed and oversaw the study, interpreted the data, and revised the manuscript. All authors have read and approved the final manuscript for publication.

\section{Competing interests}

The authors declare no competing interests.

\section{Consent for publication}

All authors have reviewed and approved the manuscript for publication.

\section{Ethics approval and consent to participate}

The study protocol was approved by the Institution Review Board and ethics committee of Chang-Gung Memorial hospital.

\section{References}


1. Kharbanda, A. B. et al. Clinical decision rule to identify children at low risk for appendicitis. Pediatrics 116, 709-716 (2005).

2. Tan, E. C. et al. Diagnosis and treatment of acute appendicitis in children: a survey among Dutch surgeons and comparison with evidence-based practice. World J. Surg. 30, 512-518 (2006).

3. Stringer, M. D. Acute appendicitis. J. Paediatr. Child Health 53, 1071-1076 (2017).

4. Bhangu, A., Søreide, K., Di Saverio, S., Assarsson, J. H. \& Drake, F.T. Acute appendicitis: modern understanding of pathogenesis, diagnosis, and management. Lancet 386, 1278-1287 (2015).

5. Snyder, M. J., Guthrie, M. \& Cagle, S. Acute appendicitis: Efficient diagnosis and management. Am. Fam. Physician 98, 25-33 (2018).

6. Wu, H. P., Lin, C. Y., Chang, C. F., Chang, Y. J. \& Huang, C. Y. Predictive value of C-reactive protein at different cutoff levels in acute appendicitis. Am. J. Emerg. Med. 23, 449-453 (2005).

7. Chen, C. Y., Zhao, L. L., Lin, Y. R., Wu, K. H. \& Wu, H. P. Different urinalysis appearances in children with simple and perforated appendicitis. Am. J. Emerg. Med. 31, 1560-1563 (2013).

8. Ebell, M. H. \& Shinholser, J. What are the most clinically useful cutoffs for the Alvarado and Pediatric Appendicitis Scores? A systematic review. Ann. Emerg. Med. 64, 365-372.e2 (2014).

9. Swenson, D. W., Ayyala, R. S., Sams, C. \& Lee, E. Y. Practical imaging strategies for acute appendicitis in children. AJR Am. J. Roentgenol. 211, 901-909 (2018).

10. Bax, T., Macha, M. \& Mayberry, J. The utility of CT scan for the diagnostic evaluation of acute abdominal pain. Am. J. Surg. 217, 959-966 (2019).

11. Acharya, A., Markar, S. R., Ni, M. \& Hanna, G. B. Biomarkers of acute appendicitis: systematic review and cost-benefit trade-off analysis. Surg. Endosc. 31, 1022-1031 (2017).

12. Lorente, L. et al. Association between serum soluble CD40 ligand levels and mortality in patients with severe sepsis. Crit. Care 15, R97 (2011).

13. Douglas, C. D., Macpherson, N. E., Davidson, P. M. \& Gani, J. S. Randomised controlled trial of ultrasonography in diagnosis of acute appendicitis, incorporating the Alvarado score. BMJ 321, 919$922(2000)$.

14. Lin, K. C., Wu, H. P., Huang, C. Y., Lin, C. Y. \& Chang, C. F. Discriminant analysis of serum inflammatory biomarkers which differentiate pediatric appendicitis from other acute abdominal diseases. Acta Paediatr. Taiwan. 48, 125-130 (2007).

15. Monneuse, $\mathrm{O}$. et al. Pain as the only consistent sign of acute appendicitis: lack of inflammatory signs does not exclude the diagnosis. World J. Surg. 34, 210-215 (2010).

16. Senhaji, N., Kojok, K., Darif, Y., Fadainia, C. \& Zaid, Y. The contribution of CD40/CD40L axis in inflammatory bowel disease: an update. Front. Immunol. 6 (2015).

17. Seibold, K. \& Ehrenschwender, M. p62 regulates CD40-mediated NFKB activation in macrophages through interaction with TRAF6. Biochem. Biophys. Res. Commun. 464, 330-335 (2015).

18. de Lizarrondo, M. S. et al. Synergistic effect of thrombin and CD 40 ligand on endothelial matrix metalloproteinase-10 expression and microparticle generation in vitro and in vivo. Arterioscler. 
Thromb. Vasc. Biol. 32, 1477-1487 (2012).

19. Liu, Z. L. et al. The CD40 rs1883832 Polymorphism affects sepsis susceptibility and SCD40L levels. BioMed Res. Int. (2018).

\section{Figures}
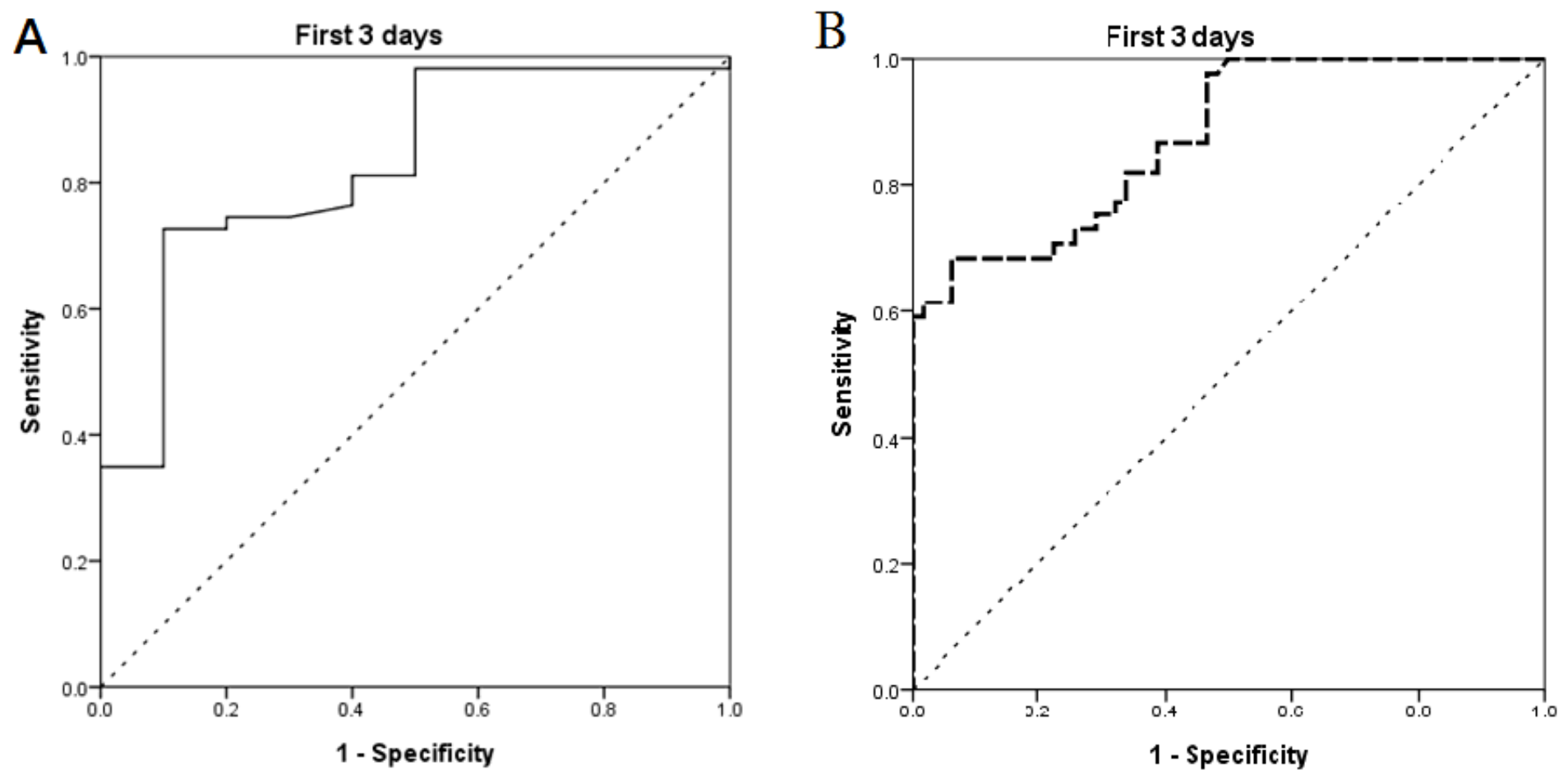

Figure 1

Receiver operating characteristic curves for SCD40L in distinguishing children with acute appendicitis from normal appendices $(A)$, and children with perforated appendicitis from nonperforated appendicitis (B)
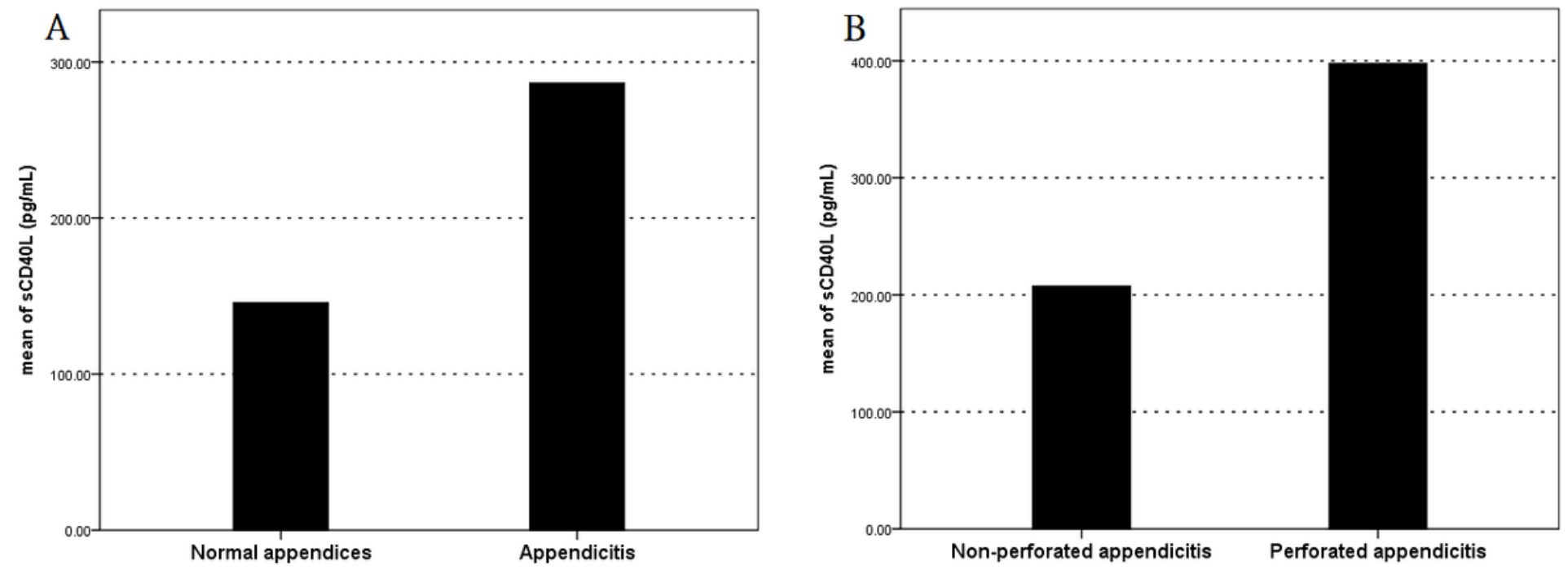


\section{Figure 1}

Mean serum SCD40L levels: (A) children with normal appendices and acute appendicitis, (B) children with nonperforated appendicitis and perforated appendicitis 